\title{
Erratum: Mental health research in African organisations: Advancing theory and practice
}

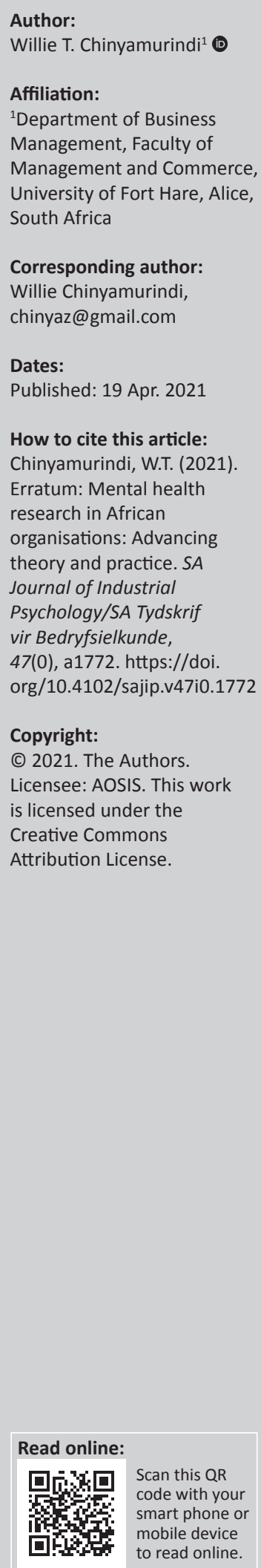

In the version of this article initially published, Chinyamurindi, W.T., (2019). Mental health research in African organisations: Advancing theory and practice. SA Journal of Industrial Psychology/SA Tydskrif vir Bedryfsielkunde, 45 (0), a1727. https://doi.org/10.4102/sajip. v45i0.1727, the article section was given incorrectly. The correct section should be Editorial instead of Original Research.

This correction does not alter the study's findings of significance or overall interpretation of the study's results. The publisher apologises for any inconvenience caused. 


\section{Mental health research in African organisations: Advancing theory and practice}

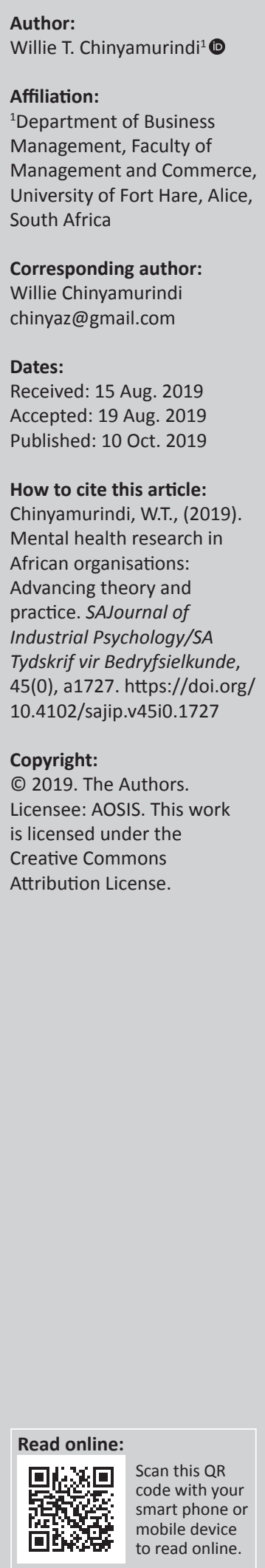

It gives me immense pleasure to introduce this special issue, entitled 'Mental health research in African organisations: Advancing theory and practice', and to have acted as a guest editor. This is a project I view as being borne out three necessities and experiences. Firstly, having personally experienced mental health challenges at key stages of my career, providing some resonance with the challenge before us. Secondly, as a researcher within the Industrial and Organisational Psychology stream, I am always inundated by requests from my participants for help concerning interventions geared towards addressing mental health issues, especially within the South African public service upon which my research has been focused over the last 3 years. Thirdly (and related to the first two points), in 2018 I received funding for a selfinitiated grant by the South African Medical Research Council to explore the issues of mental and physical health issues within the South African public service. I thought, what better way could there be to inform my current research than working through this funding opportunity by guest-editing a special issue in an important journal such as the South African Journal of Industrial Psychology. These three experiences, for me, appear to not only heighten focus on the necessity of a conversation around mental health research within the context of the African organisations, but also to ignite further inquiry into this topic beyond the special issue.

Given this background, the special issue has seven articles linked to the proposed theme. Kotze and Massyn focus on the influence of cross-cultural psychological capital on workplace psychological well-being. Based on their findings, there is a need for the development of crosscultural competencies through organisational interventions that play a role in the promotion of psychological well-being. In another article, Kheswa focuses on and illustrates the challenges around organisational resourcing and how this potentially contributes towards stress amongst health welfare professionals. Kheswa's article, despite providing subjective data, illustrates through participant quotes not only the nuances that surround the issue of resourcing but also how it relates to stress. Another article featured in this special issue, written by Vermeulen, Graupner and Jonker, is linked to the article by Kheswa and makes a clarion call for professionals like industrial psychologists to play an active role, especially within their corporate and social scope within organisations. A similar recommendation is made by Gumani within the South African Police Service.

Henn and Morgan focus on the issue of instrumentation in their article. This has been a noted challenge especially within an African context, where calls have been made for instruments that are not only sound in terms of psychometric properties but also have local relevance. The article by Henn and Morgan, based on their findings, lauds the Center for Epidemiologic Studies Depression Scale-Revised (CESD-R) and Generalised Anxiety Disorder Scale (GAD-7) as showing great promise, especially given the challenge of anxiety and depression in African and white employees in organisations. In their article, Van der Walt and Steyn emphasise the role of workplace spirituality in promoting not only psychological well-being but also ethical conduct within the organisation. Finally, Maziriri, Chuchu and Madinga focus on the issue of mental health within the small business sector, a noted area that has received scant empirical attention. The findings of their article call for more research concerning mental health within the small business context. This is especially true given the noted encouragement for the establishment of more small businesses.

I wish to thank the authors who submitted their papers for this special issue. These papers, I believe, will ignite further research interest in an important topic that affects organisations. Inote with concern the lack of papers from other African countries (outside South Africa). I am optimistic that this special issue will help us to make collaborations in addressing a universal challenge that affects all of us, whatever our locality. 